\title{
Acute respiratory failure following ovarian hyperstimulation syndrome
}

\author{
Antonello Nicolini, ${ }^{1}$ Alessandro Perazzo, ${ }^{1}$ Piergiorgio Gatto, ${ }^{1}$ Mario Santo, ${ }^{2}$ Monica Bonfiglio ${ }^{3}$ \\ ${ }^{1}$ SSD Pneumologia Ospedale di Sestri Levante (GE); ${ }^{2} \mathrm{SC}$ Medicina d'Urgenza Ospedale di Lavagna (GE); \\ ${ }^{3}$ SSD Rianimazione Ospedale di Lavagna (GE), Italy
}

\begin{abstract}
Ovarian hyperstimulation syndrome is a serious and potentially life-threatening physiological complication that may be encountered in patients who undergo controlled ovarian hyperstimulation cycles. The syndrome is typically associated with regimes of exogenous gonadotropins, but it can be seen, albeit rarely, when clomiphene is administered during the induction phase. Although this syndrome is widely described in scientific literature and is well known by obstetricians, the knowledge of this pathological and potentially life-threatening condition is generally less than satisfactory among physicians. The dramatic increase in therapeutic strategies to treat infertility has pushed this condition into the realm of acute care therapy. The potential complications of this syndrome, including pulmonary involvement, should be considered and identified so as to allow a more appropriate diagnosis and management. We describe a case of a woman with an extremely severe (Stage 6) ovarian hyperstimulation syndrome who presented ascites, bilateral pleural effusion and severe respiratory failure treated with non-invasive ventilation. The patient was admitted to the intensive care unit because of severe respiratory failure, ascites, and bilateral pleural effusion due to ovarian hyperstimulation syndrome. Treatment included non-invasive ventilation and three thoracentesis procedures, plus the administration of albumin, colloid solutions and high-dose furosemid. Severe form of ovarian hyperstimulation syndrome is observed in $0.5-5 \%$ of the women treated, and intensive care may be required for management of thromboembolic complications, renal failure and severe respiratory failure. Pulmonary intensive care may involve thoracentesis, oxygen supplementation and, in more severe cases, assisted ventilation. To our knowledge, there have been only two studies in English language medical literature that describe severe respiratory failure treated with non-invasive ventilation.
\end{abstract}

\section{Introduction}

Ovarian hyperstimulation syndrome (OHSS) is a serious and potentially life-threatening physiological complication observed in women who undergo ovarian hyperstimulation therapy. It is characterized by a wide range of clinical and laboratory manifestations caused by the simple induction of ovulation or after fertility treatment or induction of multiple follicular

Correspondence: Antonello Nicolini, SSD Pneumologia, Via Terzi 43, 16039 Sestri Levante (GE), Italy.

Tel. +39.018.532.9145 - Fax: +39.018.532.9935.

E-mail: antonello.nicolini@fastwebnet.it

Key words: ovarian hyperstimulation syndrome, massive pleural effusion, severe respiratory failure, non-invasive ventilation.

Conflict of interests: the authors declare no potential conflict of interests.

This work is licensed under a Creative Commons Attribution NonCommercial 3.0 License (CC BY-NC 3.0).

CCopyright A. Nicolini et al., 2013

Licensee PAGEPress, Italy

Italian Journal of Medicine 2013; 7:43-47

doi:10.4081/itjm.2013.43 development. ${ }^{1}$ OHSS is the result of an abnormal response to ovarian stimulation and is characterized by an excessive increase in the size of the ovaries, and of changes in the permeability of the capillaries that determine the passage of liquid out of the vascular system. ${ }^{2}$ This determines the formation of ascites and, therefore, pleural effusion with consequent hypovolemia, oliguria, hemoconcentration, electrolyte changes and, more rarely, disseminated intravascular coagulation. The less serious forms are observed in between $25 \%$ and $30 \%$ of cases of induction of multiple ovulation while the more serious forms have an incidence of $0.5-5 \% .^{2}$ Deaths have also been reported due to cerebral thromboembolism, acute renal failure, acute respiratory distress syndrome (ARDS) and cardiorespiratory arrest..$^{1-3}$ The disease has been classified in various stages on the basis of the seriousness of the condition according to Golan criteria and modifications by $\operatorname{Navot}^{3,4}$ (Table 1).

\section{Case Report}

A 41-year old woman was admitted to the emergency unit because of a rapid weight increase, abdominal distension, general malaise, increasing dyspnea and dry cough. The same patient had a little time earlier followed a protocol of controlled ovarian stimu- 
lation based on follicle stimulating hormone (FSH), gonadotropin releasing hormone (GRH) and human chorionic gonadotropin (HCG) ten days before in vitro fertilization. On admittance to the emergency unit (12 days after administration of the ovarian stimulation protocol), the patient presented the following clinical profile: respiratory rate $30 / \mathrm{min}$, heart rate $112 / \mathrm{min}$, blood pressure $95 / 65 \mathrm{mmHg}$, and body temperature $37^{\circ} \mathrm{C}$. Chest examination showed a clear reduction in breath sounds on the bottom right side and wet sounds were heard on the bottom left.

Abdominal ultrasound showed the ovaries had increased in size with a modest ascites effusion. Echocardiogram showed no pericardial effusion. Chest X-ray showed massive pleural effusion involving almost all the right lung (Figure 1). Laboratory tests showed: HCG $724.4 \mathrm{mIU} / \mathrm{mL}$, estradiol pg $4133 / \mathrm{mL}$, red blood cells $2870 \times 10^{9} / \mathrm{L}, \mathrm{Hb} 10.5, \mathrm{Ht}$ 31.6, white blood cells $14.02 \times 10^{9} / \mathrm{L}$, c-reactive protein $16.16 \mathrm{mg} / \mathrm{dL}$, sodium $132 \mathrm{mEq} / \mathrm{L}$, potassium 3.41 $\mathrm{mEq} / \mathrm{L}$, calcium $8.62 \mathrm{mg} / \mathrm{dL}$, AST $47 \mathrm{U} / \mathrm{L}$, ALT 61 $\mathrm{U} / \mathrm{L}, \mathrm{GGT} 45 \mathrm{U} / \mathrm{L}$, total protein $6.12 \mathrm{~g} / \mathrm{dL}$, albumin $3020 \mathrm{mg} / \mathrm{dL}$, ferritin $199.0 \mu \mathrm{g} / \mathrm{L}, \mathrm{LDH} 256 \mathrm{U} / \mathrm{L}$, fib- rinogen $544 \mathrm{mg} / \mathrm{dL}$, antithrombin III 87\% (normal range $75-125 \%$ ) D-dimer 1.59 (normal value 0.50 ).

Arterial blood gas $(\mathrm{ABG})$ analysis showed $\mathrm{paO}_{2}$ $29.2 \mathrm{paCO}_{2} 37.3 \mathrm{ph} 7.478, \mathrm{paO}_{2} / \mathrm{FIO}_{2} 139$, lactic acid $1.0 \mathrm{mmol} / \mathrm{L}$. The patient was, therefore, transferred to the intensive care unit and underwent thoracentesis with extraction of $1500 \mathrm{cc}$ of pleural liquid and treated with continuous positive airway pressure (CPAP) noninvasive ventilation with expiratory pressure and $\mathrm{FIO}_{2}$ $50 \%$. One hour after treatment with CPAP, ABG analysis showed $\mathrm{paO}_{2} 102 \mathrm{paCO}_{2} 36.9$ ph 7.46 and the $\mathrm{paO}_{2} / \mathrm{FIO}_{2}$ ratio had risen to 205 . It was decided not to intubate the patient. ${ }^{5}$ Respiratory and hemogasanalysis parameters are shown in Table 2. The patient was then treated with albumin, colloid and crystalloid solutions, dopamin $\mathrm{mg} / 24 \mathrm{~h}$, low weight molecular heparin (enoxaparin $4000 \mathrm{U} / \mathrm{die}$ ), broad-spectrum antibiotics (ampicillin/sulbactam $12 \mathrm{~g} / \mathrm{die}$ ) and high-dose furosemide $(250 \mathrm{mg} / \mathrm{die})$. Four days later, a clear improvement was observed in the clinical profile and the patient underwent a second thoracentesis $(1000 \mathrm{~mL})$ and chest computerized axial tomography (Figure 2). Patient condition continued to improve and two days

Table 1. Ovarian hyperstimulation classification and clinical profile.

\begin{tabular}{llll}
\hline Mild OHSS & Grade 1: & painful abdominal extension \\
\hline Grade 2: & grade 1+nausea, vomiting and/or diarrhea, increased ovarian volume \\
\hline Severe OHSS & Grade 3: & slight OHSS+ascites on echography \\
\hline Grade 5: & $\begin{array}{l}\text { OHSS, all the above }+ \text { hypovolemia with hemoconcentration }\left(\mathrm{Hct}>45 \%, \mathrm{WBC}>15 \times 10^{9} / \mathrm{L}\right), \text { reduced renal func- } \\
\text { tion }(\text { oliguria, creatinine } 1.0-1.5, \text { creatine clearance } \geq 50 \mathrm{~mL} / \mathrm{min}), \text { hepatic dysfunction, anasarca }\end{array}$ \\
\hline Chronic OHSS & Grade 6: & $\begin{array}{l}\text { ascites } \pm \text { hydrotonic, Hct }>55 \%, \mathrm{WBC} 25 \times 10^{9} / \mathrm{L}, \text { oliguria, creatinine } \geq 1.6, \text { creatinine clearance }<50 \mathrm{~mL} / \mathrm{min}, \\
\text { renal failure, thromboembolism, ARDS }\end{array}$ \\
\hline
\end{tabular}

OHSS, ovarian hyperstimulation; Hct, hematocrit; WBC, white blood cells; ARDS, acute respiratory distress syndrome.

Table 2. Respiratory and hemogasanalysis parameters.

\begin{tabular}{lcccccc}
\hline Parameters & $\mathbf{0 ~ h}$ & $\mathbf{1} \mathbf{h}$ & $\mathbf{1 2} \mathbf{h}$ & $\mathbf{2 4} \mathbf{h}$ & $\mathbf{4 8} \mathbf{h}$ & $\mathbf{3 6} \mathbf{h}_{\text {suspension }}$ \\
\hline $\mathrm{RF}$ & 36 & 30 & 27 & 25 & 22 & 19 \\
\hline $\mathrm{CPAP}$ & - & 6 & 16 & 8 & 8 & 5 \\
\hline $\mathrm{FIO} \%$ & 21 & 50 & 45 & 40 & 30 & 25 \\
\hline $\mathrm{PaO}_{2}$ & 29.2 & 102 & 108 & 108 & 100 & 103 \\
\hline $\mathrm{PaCO}_{2}$ & 37.3 & 36.9 & 35.7 & 33.0 & 34.1 & 35.2 \\
\hline $\mathrm{Ph}$ & 7.47 & 7.46 & 7.49 & 7.47 & 7.45 & 7.43 \\
\hline $\mathrm{HCO}_{3}$ & 21.7 & 22.6 & 26.2 & 25.5 & 24.8 & 24.2 \\
\hline $\mathrm{PaO}_{2} / \mathrm{FIO}_{2}$ & 139 & 205 & 240 & 272 & 333 & 412 \\
\hline $\mathrm{Lactic} \mathrm{acid}(\mathrm{mmol} / \mathrm{L})$ & 1.0 & 1.1 & 0.9 & 0.7 & 0.7 & 0.6 \\
\hline
\end{tabular}

$\mathrm{RF}$, respiratory frequency; CPAP, continuous positive airway pressure; $\mathrm{FIO}_{2} \%$, oxygen inspiration fraction; $\mathrm{PaO}_{2}$, arterial oxygen pressure; PaCO , arterial carbon anhydride pressure; $\mathrm{HCO}_{3}$, hydrogen carbonate; $\mathrm{P} / \mathrm{F}, \mathrm{PaO}_{2} / \mathrm{FIO}_{2}$ ratio. 
later she was transferred to the pneumology department of the hospital in Sestri Levante. Here she had a third thoracentesis $(800 \mathrm{~mL})$ carried out under echography guidance (Figure 3). Seven days later, echography and chest X-ray carried out the day before the patient was discharged showed that the pleural effusion was almost completely reabsorbed (Figure 4). Given her general good condition, the patient was discharged.

The patient has given her informed consent to the treatment and to the publication of her case report.

\section{Discussion and Conclusions}

There have been some sporadic reports in the literature of the clinical manifestations of OHSS, such

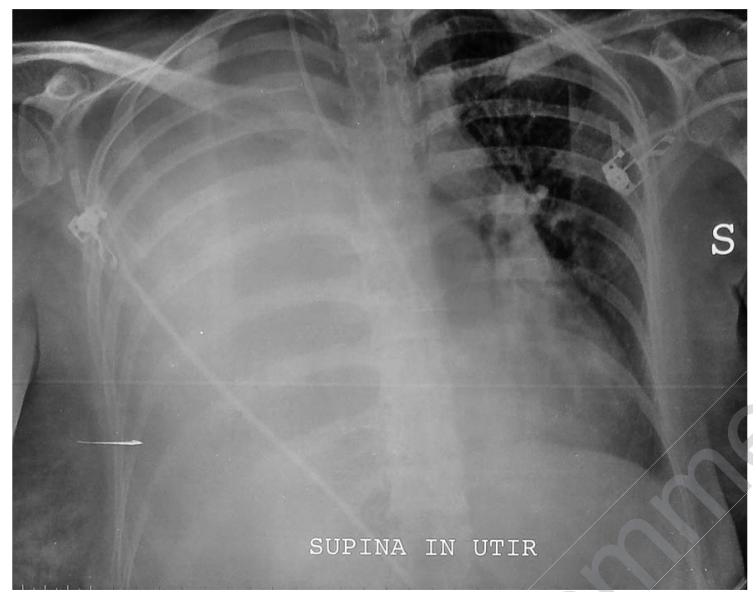

Figure 1. Chest X-ray carried out in the intensive care unit showing almost complete opacty in the right lung with contralateral mediastinal shift due to massive pleural effusion.

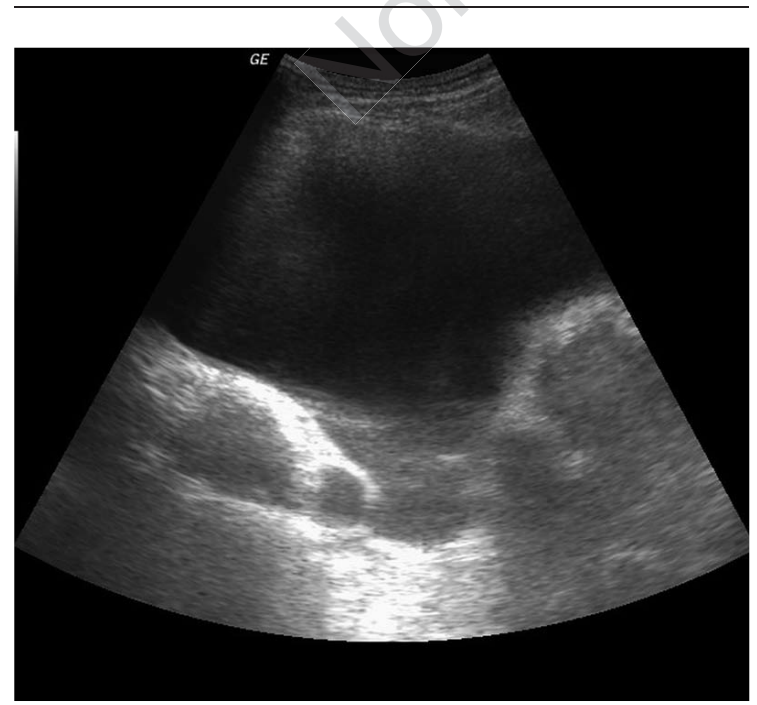

Figure 3. Chest echotomography: evidence of moderate pleural effusion. as respiratory complications (in particular pleural effusion), and ascites effusion, considered the main disease symptom, also confirmed by the few pulmonology reports. ${ }^{6-10}$ However, cases in which pleural effusion was the only disease symptom have also been described. ${ }^{7,11,12}$ OHSS is characterized by the flow of extravascular liquid resulting in depletion of intravascular liquid and the development of effusions, in particular ascites and pleural effusions. It is thought that pleural effusion is mainly due to the high estrogen level, to an increase in vascular endothelial growth factor (VEGF), of cytokines such as IL-2, IL6 and IL- 8 , and finally of tumor necrosis factor- $\alpha$ (TNF- $\alpha$ ), usually found in severe forms OHSS. ${ }^{10}$ Cases of unilateral pleural effusion (often right side) with minimum or absence of ascites effusion have al-

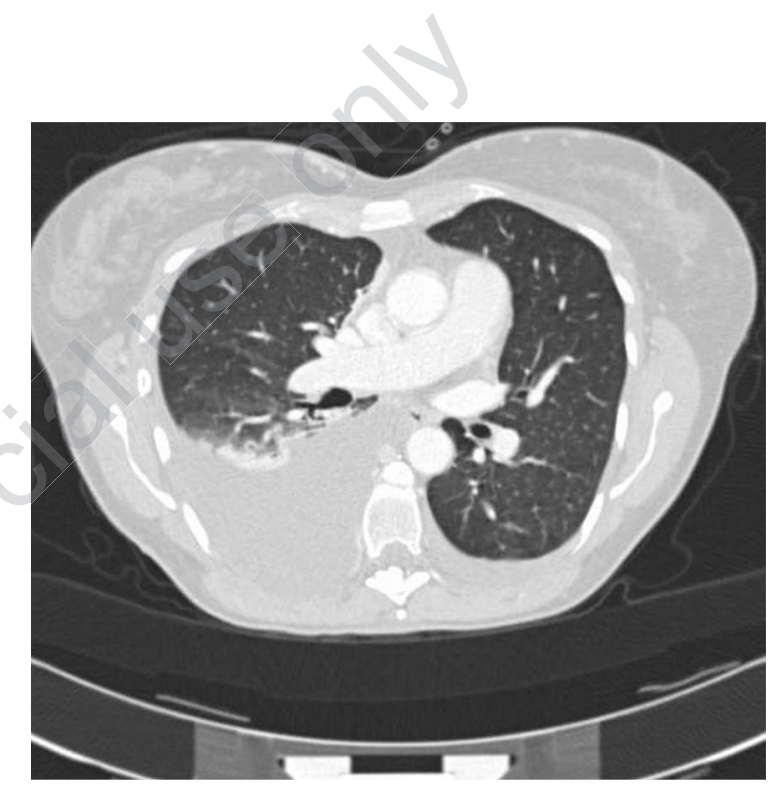

Figure 2. Chest computerized tomography: bilateral pleural effusion with clear right prevalence.

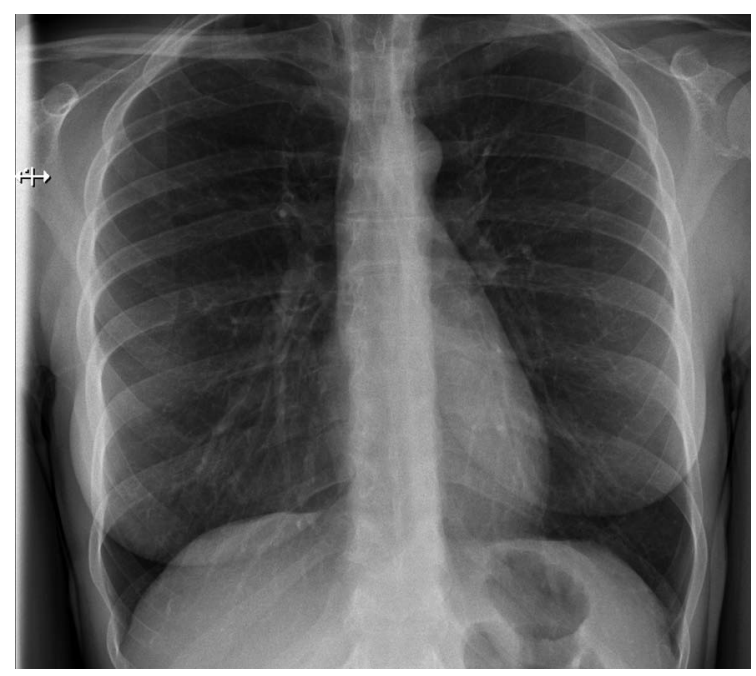

Figure 4. Chest X-ray before discharge showing the almost complete resolution of the right-hand pleural effusion. 
ready been described in literature, even though these are rare. ${ }^{13,14}$

Various hypotheses have been developed regarding the physiopathology of massive pleural effusion in the absence of ascites effusion: the flow of ascites liquid in the pleural cavity through the diaphragmatic lymphatic system, as in cirrhosis and Meigs' syndrome, the presence of anatomical defects in the diaphragm membrane, more frequent in the right hemidiaphragm and prevalent in females. Rupture of these small malformations caused by the increased pressure resulting from the ascites and the negative physiological pressure in the chest could quite convincingly explain the presence of massive right pleural effusion in the absence or small presence of ascites effusion, such as that seen in our patient. ${ }^{13,14}$

With the progressive evolution of the disease lifethreatening complications can develop. These include hypovolemia, hemorrhagic syndromes, hepatorenal syndromes, thromboembolism and ARDS. ${ }^{13}$

Different risk factors have been described related to the seriousness of the syndrome: age under 35 years, low body mass index, polycystic ovary syndrome, ${ }^{2}$ atopic syndrome, pregnancy. ${ }^{14}$ The syndrome has been classified in six levels of severity according to the Golan and Navot clinical criteria (Table 1).

In particular, in $1992 \mathrm{Navot}^{3}$ added new criteria to define severe OHSS and identify life-threatening factors (Table 3). According to this classification, our case presents intermediate characteristics between grade 5 and grade 6 . Furthermore, the presence of massive homolateral pleural effusion and the level of severity of the gas exchange deficit $\left(\mathrm{paO}_{2} / \mathrm{FIO}_{2} 139\right)$, together with a respiratory profile that, according to

Table 3. Criteria for the definition of severe and lifethreatening ovarian hyperstimulation.

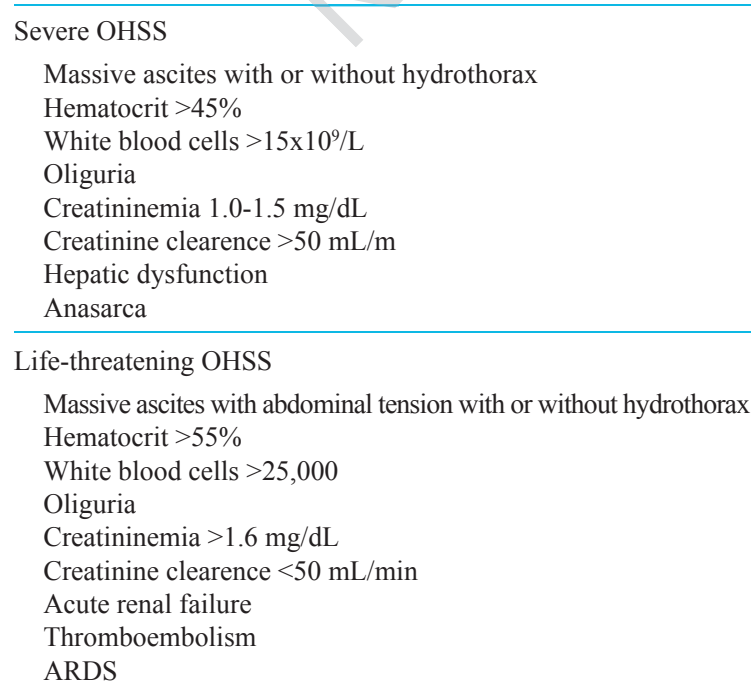

OHSS, ovarian hyperstimulation; ARDS, acute respiratory distress syndrome. the 1994 classification, ${ }^{15}$ could be described as acute lung injury/ARDS, ${ }^{16}$ could lead to our patient being classified as having among the more critical forms. The presence of massive pulmonary edema is rarely reported in the syndrome and is sometimes fatal, ${ }^{17}$ while pulmonary thromboembolism is more frequent $(12 \%){ }^{2}$ Deep venous thrombosis is even more frequent, particularly in the upper body, as is arterial thrombosis, for which a hypercoagulability mechanism is probably involved. ${ }^{2,18}$ This could be the reason for the increased D-dimer levels. The tests carried out did not suggest a diagnosis of pulmonary embolism and the respiratory profile did not seem to us to explain the presence of the massive pulmonary pleural effusion, probably associated with low load interstitial-alveolar acute pulmonary edema, as shown by the prompt response to CPAP therapy.

The use of non-invasive assisted ventilation has been described in the literature. There are few cases in the English language literature of which one was a patient treated with emergency laparatomy because of the massive ascites effusion and abdominal hemorrhage. ${ }^{19,20}$

In conclusion, a form of severe OHSS should be suspected in any female patient who presents ascites and/or pleural effusion with a case history of controlled ovarian stimulation. Although rare, this syndrome requires a multidisciplinary approach because of the risk of possible multi-organ complications and of signs and symptoms that could be life threatening.

\section{References}

1. Vassiliadis A, Schillaci R, Sciacca GM, Catalano G. La sindrome da iperstimolazione ovarica. Riv Ital Ost Gin 2006;9:485-91.

2. Gouez A, Naudin B, Grynberg M, Mercier F-J. Le syndrome d'hyperstimulation ovarienne. Ann Franc Anesth Reanim 2011;30:353-62.

3. Navot D, Berg RPA, Laufer N. Ovarian hyperstimulation syndrome in novel reproductive technologies: prevention and treatment. Fertil Steril 1992;58:249-61.

4. Golan A, Ron-El R, Herman A. Ovarian hyperstimulation syndrome: an update review. Ostet Gynecol Surv 1989;6:430-40.

5. Antonelli M, Conti G, Esquinas A, et al. A multiple-center survey on the use in clinical practice of noninvasive ventilation as a first-line intervention for acute respiratory distress syndrome. Crit Care Med 2007;35:18-25.

6. Roden S, Juvin K, Homasson JP, Israel-Biet D. An uncommon etiology of isolated pleural effusion: the ovarian hyperstimulation syndrome. Chest 2000;118;256-8.

7. Aldawood AS, Felenbam AA. Isolated unilateral pleural effusion as the only manifestation of the ovarian hyperstimulation syndrome. Saudi Med J 2003;12:1397-9.

8. Altas F, Ugcun I, Moral H, et al. Pleural effusion due to the ovarian hyperstimulation syndrome. Tuberk Torakz 2003;51:48-51. 
9. Semba S, Moriya T, Youssef EM, Sasano H. An autopsy case of ovarian hyperstimulation syndrome with massive pulmonary edema and pleural effusion. Pathol Int 2000;50:549-52.

10. Yildizhan R, Adali E, Kolusari A, et al. Ovarian hyperstimulation syndrome with pleural effusion: a case report. Cases J 2008;1:323-5.

11. Rabinerson D, Shalev J, Royburt M, et al. Severe unilateral hydrothorax as the only manifestation of the ovarian hyperstimulation syndrome. Gynecol Obstet Invest 2000,49:140-2.

12. Gupta S, Sathya B, Paddhy N, et al. Isolated bilateral pleural effusion as the sole manifestation onset ovarian hyperstimulation syndrome. J Hum Reprod Sci 2009;2:83-6.

13. Loret de Mola JR. Pathophysiology of unilateral pleural effusions in the ovarian hyperstimulation syndrome. Hum Reprod 1999;14:272-3.

14. Thomas F, Kalfon P, Niculescu M. Acute respiratory failure, lactic acidosis, and shock associated with compressive isolated right pleural effusion following ovarian hyperstimulation syndrome. Am J Med 2003;114:165-6.
15. Myrianthefs P, Ladakis C, Lappas V, et al. Ovarian hyperstimulation syndrome (OHSS): diagnosis and management. Intens Care 2000;26;631-4.

16. Bernard GR, Artigas A, Bringham K1.The American-European Consensus Conference on ARDS: definitions, mechanisms, relevant outcomes and clinical trial coordinations. Am J Resp Crit Care Med 1994;149:818-24.

17. Semba S, Moriya T, Youssef EM, Sasano H. An autopsy case of ovarian hyperstimulation syndrome with massive pulmonary edema and pleural effusion. Pathol Intern 2000;50:549-52.

18. Tavmergen E, Ozcakir HT, Levi R, et al. Bilateral jugular venous thromboembolism and pulmonary emboli in a patient with severe ovarian hyperstimulation syndrome. J Obst Gynaecol Res 2001;27:217-20.

19. Kawamura G, Ito N, Hanaoka K, Yamada Y. Anesthetic management of a patient with severe ovarian hyperstimulation syndrome. Masui 2009;58:360-2.

20. Talawar P, Rewari V, Sinha R, Trikha A. Severe ovarian hyperstimulation syndrome: intensive care management of two cases. J Obstet Anaesth Crit Care 2011;1:92-5. 